\title{
Gendered Perspectives on Refugee Determination In Canada
}

\author{
Tanya Aberman
}

\begin{abstract}
This article discusses refugee determination from an intersectional perspective to unpack the impacts of gender on the refugee determination hearing in Canada. The article highlights the importance of dominant discourses in a legal context, focusing particularly on how discursive constructions of subjectivity affect refugee determination where claimants' trustworthiness depends not only upon their abilities to describe their past experiences, but also how well their story corresponds with dominant discourses about refugees. It also discusses how these dominant discourses are racialized, gendered, and hetero-normative, and how feminist theories of intersectionality could be of use to deconstruct the ways they affect different groups of refugee claimants. The article concludes by considering the implications of the newly shortened timelines in refugee adjudication.
\end{abstract}

\section{Résumé}

Cet article traite de la détermination du statut de réfugié de façon à évaluer l'impact de l'appartenance sexuelle dans les audiences d'admission au statut de réfugié au Canada. On y souligne l'importance des discours dominants dans le contexte légal; plus particulièrement, on y examine comment les récits subjectifs affectent l'admission au statut de réfugié lorsque la fiabilité des témoignages des demandeurs repose non seulement sur leur capacité à décrire leurs expériences passées, mais également sur l'adéquation de leurs témoignages avec ces discours dominants sur les réfugiés. On y examine comment ces discours dominants contiennent des éléments de racisme, de sexisme et d'hétéronormativité, et comment les théories féministes d'intersectionnalité pourraient contribuer à déconstruire leur influence sur les divers groupes de demandeurs d'asile. Cet article conclut en considérant l'impact du raccourcissement des délais des processus de demande d'asile au Canada.

\section{Introduction}

$\mathrm{R}$ efugee determination has become an increasingly debated and contested process in Canada within the last few years, culminating with the implementation in December 2012 of Bill C-31, Protecting Canada's Immigration System Act. Questions have circulated over who is a "genuine" refugee, who is not, who is a "bogus" claimant, and how that determination should be reached. New procedures are supposed to offer a progression towards answering these questions, yet many refugee advocates have significant doubts.

One aspect of the old system that has been maintained within the implementation of the new one is the oral hearing. As a result of the 1985 Supreme Court Singh decision, all refugee claimants should have access to a full oral hearing to explain their claim, and adjudicators should assess their case on the basis of knowledge of conditions in the country of origin, as well as a recognition of the claimant's subjective fear of persecution. Within this hearing process, it has been argued that claimants must "produce a successful refugee image"1 in the recounting of their experience of persecution, an image that is based on intersecting essentialized ideas of gender, race, sexuality, and ability, among others. The Western-centric preconceived ideas about the racialized and orientalized ways refugee claimants should perform their gender and their fear within their narratives of persecution can have significant impacts on the adjudication of their claim. While the new determination process has been implemented, this article will focus on adjudication prior 
to December 2012, since little research is available on the impact of the changes. However, it will be argued that the findings can have implications for the new processes and subsequent related research.

Looking at the identity categories constructed to frame "refugeeness" in the Canadian determination system prior to Bill C-31 from an intersectional analytical framework, this article will draw on what McCall identifies as the intracategorical complexity approach, where "the point is not to deny the importance-both materially and discursive-of categories but to focus on the process by which they are produced, experienced, reproduced, and resisted in everyday life." ${ }^{2}$ Categories such as gender, race, sexuality, and ability will be deconstructed to allow for a broader theoretical and analytical understanding of how interactions and power relations contribute to the production and reproduction of these categories. This will also allow for the recognition of a greater diversity of experiences beyond those expected from reified identity constructs, ${ }^{3}$ while at the same time recognizing the material implications of categories within people's lived realities. Refugee subjectivity is constituted and reconstituted at different moments, from the point of fleeing a country of origin, to the experiences of migration, to the refugee determination process, based on complex and contradictory discourses, interactions, and embodied experiences. While refugee claimants interact with numerous and diverse actors and institutions throughout their forced migration, state policies and government agencies play a specific role in imposing this refugee subjectivity on claimants, ${ }^{4}$ a "damaged" subjectivity that the claimant may or may not adopt for a multitude of reasons. 5 These designated identities may or may not subsequently affect their determination as "genuine" refugees.

This article reviews the relevant theoretical and empirical literature from diverse disciplinary approaches primarily spanning the last twelve years, since the implementation of the Immigration and Refugee Protection Act in 2002. While the majority of the research relied upon was based within the Canadian context, a few articles were selected that focused on refugee determination in other locations as a result of their unique analysis and relevant explanatory value within the Canadian system. The literature discussed focused primarily on specific identity constructs, frequently including certain intersectionalities to further nuance the discussions. By bringing them all into conversation in this article, the possibility of a more robust understanding of the ways intersecting identities affect refugee determination is offered. While not all intersectionalities could be analyzed to the same extent, there is room for further research, particularly as the new refugee processes include different markers, such as country of origin and means of migration.

\section{Intersectionality}

Intersectionality was introduced as a concept and framework that would challenge a dominant form of feminist analysis that was seen to essentialize women's experiences, ignoring and rendering invisible certain other knowledges and realities. Coined and elaborated by Kimberlé Crenshaw in 1989, intersectionality enabled an analysis of a multitude of experiences without necessarily conceptualizing specific identities as inherent or static. As an analytical perspective, it has enabled a more nuanced approach to conceptualizing the ways inequality, discrimination, and oppression intersect and overlap. It also allows for a recognition of the limitations of any single analytical category or lens. Instead, intersectionality highlighted "the relationships among multiple dimensions and modalities of social relations and subject formations." ${ }^{\circ}$ Therefore, within a feminist intersectional framework, identity categories are understood as relational. They are based on historical contexts, social constructs, and power relations, with no one category carrying more importance at all times, though individual categories may be focused on at different moments, for different purposes. This type of approach allows for an emphasis on the "constructedness" of social identity categories and the processes that produce and reproduce them.7 As such, it is possible to avoid constructing lived experiences as homogeneous and to "remain sensitive to possible new admissions, de-namings and exclusions," 8 while these categories change and evolve as people "cooperate or struggle with each other, with their pasts, and with the structures of changing economic, political and social worlds."9

The deconstruction of identity categories, along with a theoretical analysis of how the categories intersect in the conceptualization of subjectivities, is part of understanding how inequalities are continuously reproduced. Since symbolic and material violence is tied to relational identity categories, understanding how they are constituted recognizes the power relations that are maintained through these processes, and therefore deconstructing them can open possibilities for social change. ${ }^{10}$ This change becomes possible at different moments and on different operational scales, since identity is constituted at the micro, meso and macro level. It is argued that an intersectional approach can offer a historically and socially contextualized analysis at the level of the body, the household, the regional, the national, and the supra-national, ${ }^{11}$ and that social change is subsequently possible on all those levels.

McCall offers three types of intersectional analysis, suggesting that methodological approaches used thus far have fallen into one of the three, labelled as anti-categorical complexity, inter-categorical complexity, and intra-categorical complexity. She elaborates these in terms of their approach 
to categories, how they interpret and analyze categories to explore and explain social life. Anti-categorical complexity considers social interactions and lived experiences, subjects and structures, as too complex to enable any fixed categories to describe them in any realistic way. At the other end of the continuum is the inter-categorical complexity approach, which requires the strategic use of categories to highlight inequalities between social groups and the evolution and reproduction of these inequalities. Finally, intra-categorical complexity deconstructs naturalized boundaries and the processes that produce these boundaries, as in the first approach, but acknowledges the "stable and even durable relationships that social categories represent at any given point in time."12 Therefore, it offers the tools to critically analyze identity constructs, their production and reproduction, while at the same time recognizing their ongoing relevance within social structures and their material implications. It is this last approach that I shall draw on throughout this article.

Academic research and writing on migration have historically framed migrants as disembodied, rational actors, reacting to social, economic, and political conditions. These approaches have been widely critiqued, and intersectional approaches have increasingly gained prominence. The recognition that migration is a complex process, influenced and affected by competing forces, expectations, and power relations, allowed for more nuanced approaches, enabling a representation of the heterogeneity of migrants while taking seriously migrants' divergent experiences. The introduction of migrants' diverse identities was an influential and critiqued shift in migration studies. The early move to study dichotomous gender relations was an important step to highlighting the divergent experiences of women and men, while enabling an easy shift within quantitative research. However, it has been argued that this approach was limited in the scope of its analysis of the power relations involved. ${ }^{13}$ Migration is a gendered, racialized, and classed process, which requires an analysis that conceptualizes the complexity, malleability, and rigidity of these categories. It is an embodied process, ${ }^{14}$ which is experienced beyond the inflexible categorizations of race and class and the dichotomous and hetero-normative conceptualizations of gender. Migrants are categorized in different ways throughout their movements, as certain rigid constructs stick to some bodies in certain contexts and others shift and change. As a result, the migrants' subjectivities become constituted and reconstituted through the processes, interactions, and acts of migration.

Asylum seekers, refugees, and others who have been displaced as a result of forced migration may experience the process and the articulation of identity and subjectivity in ways that may or may not differ from other migrants at various points. Frequently, in order to be understood socially, politically, and economically as forced migrants, their subjectivity must reflect and reaffirm a predefined experience in which distinct expectations regarding gender, race, sexuality, and ability are central. These constructed categorizations fall into a particular representation of "helplessness" and victimhood intrinsic in Western ideas of refugeeness. While under international law the definition of a refugee has remained constant, refugeeness has changed quite significantly. As Judge argues, with the end of the Cold War, the political-legal approach to the conceptualization of refugeeness shifted from protecting a political actor to managing a helpless victim. ${ }^{15}$ Yuval-Davis also emphasizes this point, explaining that the formal refugee convention was developed heavily in the West to accept political dissidents from the Eastern Bloc, while post-9/11 state policies define actors resisting their governments as potential terrorists. ${ }^{16}$ Therefore, not only did forced migration become depoliticized, criminalized, and de-historicized at the point of fleeing and arriving, this shift to victimization also individualized refugee subjectivity, which facilitated Othering and paternalistic "protection."17 These shifts in the construction of refugee subjectivity had important intersectional implications based on "who" could be a victim, in what ways, and who became a criminalized "bogus" claimant.

\section{Canadian Policy}

Political systems and civil society in destination countries play important roles in constituting migrant subjectivity through discourses, power relations, and embodied interactions. While Canadian government officials purport the country's immigration policy to be efficient, fair, and compassionate, ${ }^{18}$ and Canadians are lauded as welcoming and hospitable, the system has historically and contemporarily proven to be highly exclusionary, based on racialized, classed, and gendered admission criteria. From racist policies that have directly excluded Chinese, Japanese, South Asian, and Indigenous populations from full citizenship, to the "Women's Division" created within the immigration department to "care" for immigrant women who could be deported if found to have engaged in sexual relations outside of marriage, the policies have historically contained and excluded particular gendered and racialized bodies. ${ }^{19}$ These policies have shifted and changed through the last century, with differing communities tolerated or targeted at different moments. Therefore, while "exclusions of the past were explicitly racist and were justified by discourses of racial purity and biological degeneration, present day racist constructions heighten the dominance of classifications ... and are mediated more by cultural stereotypes than by biological typologies." ${ }^{2}$ Though current policies may be more subtle in their exclusionary tactics, the intersections 
of gender, race, and class are still predominant factors in determining which migrants experience efficient and compassionate immigration as promoted, and which do not. Richmond exposes the more recent, predominantly subtle exclusionary tactics, such as imposing visas for the travel of certain nationals, limiting the number of visas to citizens of certain countries, and establishing few offices able to process these visas or other applications (as opposed to the large number able to process American and European applications). ${ }^{21}$ As a result of these policies, migrants are conceptualized in specific ways that generalize their experiences and desires, marking some as "desirable" new society members and the rest as "Other," to be limited, controlled, and contained. These conceptualizations allow for "cardboard cut-out characterizations," which Lewis argues "is one key strand that runs across the struggles over citizenship between those who govern and those who are governed," reifying the differences and hierarchies between citizen and non-citizen, those who can become citizens and those who cannot. ${ }^{22}$

As a signatory to the 1951 UN Convention Relating to the Status of Refugees and the 1967 Protocol, Canada has internationally recognized obligations towards refugee protection. These obligations include recognizing the international definition of who qualifies as a refugee, the rights that must be accorded to those who qualify, and not returning individuals to states where their lives or freedom are threatened. Despite the provisions of the convention and protocol, refugees attempting to reach Canada for protection are subject to the same subtle, yet powerful exclusionary practices described above. While some are able to claim asylum from outside Canada's borders, the persecution faced by others obliges them to flee to Canada as a first step, and subsequently make a refugee claim. For those who are able to travel to Canada and then make their claim, either at the border or inland, the refugee determination process establishes whether or not they are able to receive Canadian protection and citizenship rights. Though this process is mandated under the international convention, specific policies are under the auspices of state sovereignty and have been progressively designed to decrease the number of refugee claimants through administrative means. ${ }^{23}$ Consequently, the process has become increasingly complex and difficult to navigate in order to exclude many applicants. As a result, refugee claimants who are unable or unwilling to complete the process for any reason are largely portrayed as "bogus" or "undeserving," and rather than recognizing the multitude of reasons people are unable to achieve Canadian protection, they are criminalized and demonized.

The Canadian refugee determination process involves a complex and intricate series of appointments to make and attend, forms to fill out and file, and the final hearing to prepare for, where claimants are expected to freely and fully tell their story of persecution without fear or intimidation. Failure to complete any aspect appropriately, or within the precisely defined timeline, can lead to the rejection of the claim. This process has become increasingly stringent with the implementation of Bill C-31, where the timelines have been severally shortened and claimants have been categorized in ways to specifically disadvantage certain individuals and groups. While many of these changes are relevant to the analyses developed in this article, detailed explanations of the new system are beyond the scope. However, links will be made at the end of the article, along with suggestions for future research.

Though each stage of the refugee determination process has its own complications and complexities, the hearing itself is where all of the information provided at each stage, as well as an oral description of the claimant's experience of persecution, are supposed to come together and the final decision is made. Therefore, the Immigration and Refugee Board (IRB) members who make the final decisions have enormous power to grant protection, or to maintain narrow definitions of "refugeeness" and subsequent low acceptance rates. These are necessarily complex decisions to make, since, as Rouseau et al. point out, "The decision-maker [must] have a sufficient knowledge of the cultural, social and political environment of the country of origin, a capacity to bear the psychological weight of hearings where victims recount horror stories, and of consequent decisions which may prove fatal." 24

The hearing itself is declared to be a non-adversarial process, where officials are trying to uncover the truth of the claimants' situations, and asylum seekers are supposed to unreservedly share the narratives of their experiences. However, this is often a contradictory approach, since content and style of questions are at the discretion of the board member, ${ }^{25}$ and the methods and rhetoric of these officials range from generous protection to an implied understanding of the claimant as a "liar" and a "criminal."26 Claimants are thus left unsure of how to approach the hearing and how to represent their experiences, and the choice has important consequences for adjudication.

Adjudicators are supposed to grant claimants the benefit of the doubt where documentation is lacking or unavailable as the result of the ambiguities and subjectivities involved in the description of fear. ${ }^{27}$ Within the "well-founded fear of persecution," there are requirements for both subjective and objective fear. ${ }^{28}$ Therefore, not only do claimants need to appear genuinely fearful of their situation, there must also be documentation to support this fear. Despite the low burden of proof mandated and the benefit of the doubt 
that is supposed to side with the claimant, many claims are excluded for lack of credibility or an implausibility as determined by often Western-centric conceptualizations of gendered and racialized fear.

\section{Identity, Subjectivity, and the Refugee Determination System}

Refugee determination has been criticized as a male-centred process, as questions were widely raised regarding the male dominance in refugee claims and the masculinized construction of the refugee/persecuted dissident. Following the signing of the Refugee Convention and subsequent protocol, the initially recognized forms of persecution were conceptualized in the West within what has been identified as more masculine experiences. Adjudication was therefore determined on related expectations, thus ignoring other forms of persecution. In order to address these issues and biases, the Canadian government was the first to develop and implement the Gender-Based Persecution guide in 1993, with many other states following suit. The resulting guidelines constituted a significant advancement in recognizing different forms of persecution and providing board members new contexts for adjudication. Consideration was extended to persecution related to kinship, gender discrimination, and violence by public authorities or individuals where the state is unable or unwilling to provide protection (including domestic violence), or discrimination or violence based on perceived transgression of legal, religious, or social expectations of the way gender should be enacted. ${ }^{29}$ However, these guidelines also build on certain constructs of gender that may exclude claimants who do not conform. Moreover, despite the important addition of domestic violence as a recognized form of persecution, Sadoway argues, in cases where the same forms of violence are common in the destination country, refugee designation may be harder to achieve, as it may simply be considered a larger societal problem. ${ }^{30}$

Significant effort has been devoted to acknowledging and mainstreaming the recognition of gender-based violence and persecution in Canadian refugee determination procedures. While this has been lauded by many and recognized as a best practice by other governments and institutions, others have critiqued the essentializing and cultural relativism that has occurred as a result of the guidelines. Therefore, conforming to narrowly defined constructs has been crucial in order to be recognized within the guidelines. For example, cases where women fear female genital mutilation, forced marriage, or bride burning may be more acceptable, building on colonial tropes and constructing the female-identified claimant as a victim in need of saving, while demonizing her country of origin. This consolidates an "us" and "them" discourse, which constructs "bad patriarchies" as dominant in distant countries and on foreign bodies, ${ }^{31}$ disavowing the inherent local patriarchal structures and violence. It also positions the adjudicator as the chivalrous protector, able to save such claimants from their violent culture.

This accepted narrative of victimhood constitutes claimants' subjectivities through specific intersections of race, gender, religion, and sexuality, narrowing the spectrum of claimants who can meet the necessary expectations. Throughout there are dominant and intersecting constructs of a particular form of hetero-normative femininity, with its associated vulnerability, and a "cultural" racialization based on demonizing specific cultures and religions as different and violent. This diminishes and falsifies women's real claims, obfuscating their political opposition to oppressive norms by framing their positionality as victims of their society. ${ }^{32}$ It nearly eliminates women's ability to claim asylum on grounds of resistance ${ }^{33}$ and if the claimant shows too much strength, beyond what is conceptualized as appropriate within these constructs, she may be refused on the grounds that she should be able to protect herself. 34

Moreover, the intersectional construction of women's vulnerability within this paradigm becomes almost inseparable from hetero-normative motherhood. This construct creates women and children as "virtually one word,"35 a "hybridized figure of vulnerability," which not only infantilizes women and their encounters, but once again acts to depoliticize women's experiences. ${ }^{36}$

Also included within the Canadian Gender Guidelines is persecution based on sexual identity and orientation. Sexual orientation and gender identity involve a diverse spectrum of perspectives, constructs, and self-articulations. Within these categories of claims, the intersecting constructions of gender, sexuality, race, age, and class also have important implications for adjudication. Western-based stereotypes about how sexuality should be experienced and performed by different people in various locations can affect the success of these claims. ${ }^{37}$ This erases more complex subject positions and ignores differing realities, ${ }^{38}$ delegitimizing the experiences of those who are unable to negotiate the "culturally proscribed identity narratives ... associated with a normative Euro-American sexual identity formation." 39 Those who do not, or cannot, conform to gendered constructs and the related experiences that are expected have their identity and orientation questioned and challenged. These stereotypical understandings of how sexuality should be performed involve the frequenting of gay bars and clubs, and embodiment of specific gendered characteristics, such as the adoption of masculine traits by female-identified claimants and the effeminacy of male-identified claimants. ${ }^{40}$ Thus the intersections of class, age, and ability become particularly 
evident in the expectations regarding claimants' lifestyles. While claimants from urban areas with access to Western media may be aware of others who identify in similar ways, but look, speak, and behave differently, others without such resources may be confronted with these stereotypes only after arrival in Canada, if at all. ${ }^{41}$ This puts claimants from more rural areas, or without access or ability to utilize technology, at a possible disadvantage.

This process often also involves the demonization of the country of origin, casting other locations and populations as homophobic and violent. Claimants from states in which LGBTQ communities are publicly criminalized often receive the most sympathy from board members, ${ }^{42}$ further reinforcing "Us" versus "Other" dichotomies. Therefore claimants' citizenship must intersect with their other identity constructs in the articulation of their experience of persecution.

LaViolette illustrates how the IRB's handling of sexual orientation and gender-identity claims has evolved over the last two decades, concluding that LGBTQ claimants are still at a disadvantage with regards to objective evidence of persecution. ${ }^{43}$ She outlines how the lack of human rights documentation on issues of sexual orientation and gender identity has hindered claimants, with adjudicators citing the lack of documentation as an absence of persecution. However, she also highlights the contradictory fact that documenting violence and persecution of LGBTQ individuals may be particularly dangerous or even impossible in situations and locations where homophobic violence is widespread. On an individual level, this may also disadvantage claimants, where social stigma and violence may have prevented them from reporting particular incidents, leaving them with little or no proof of assaults or attempts to seek state protection. LaViolette also points to the fact that the agents of persecution may be individuals, whether family or community members, leaving the possibility of state protection in question. Moreover, as Murray explains, the credibility of a sexual orientation claim is often also based on internal, "unspoken or unspeakable qualities, desires and practices," which claimants must now freely discuss. 44

Building on the understanding that sexual orientation is "flexible and fluid," Rehaag investigates the outcomes of refugee claims based on bisexuality. ${ }^{45} \mathrm{He}$ argues that bisexual claimants are further disadvantaged within the refugee determination process that misidentifies and misinterprets their lived experiences. While sexual-minority refugee claimants on average have success rates similar to those of other claimants, people seeking asylum from persecution based on bisexuality have much lower acceptance rates. ${ }^{46}$ These transgressions of gender norms are read by IRB adjudicators as shifting and changeable, which is then interpreted as a fraudulent way to claim asylum. Rehaag found that in a majority of cases claimants were not believed, and femaleidentified claimants were refused much more frequently than male-identified bisexual claimants. Dichotomous constructions of gender and sexuality thus affect refugee adjudication; experiences outside of these binaries are misinterpreted in order to fit them within specific Western categories that do not represent people's different realities. Compartmentalizing identities and lived experiences may simplify adjudication based on precedents set and experiences expected, as board members work to differentiate "genuine" refugees from other claimants. However, this may put the lives of people at risk as they fail to conform to expectations of a "genuine" refugee.

Since the end of the Cold War, the shift from the construction of refugees as political dissidents actively contesting their government, to helpless "victims" unable to defend themselves, has had important implications for male-identified refugee claimants as well. Those who "may not fit comfortably into the confines of these discourses of the ideal refugee, with exceptional talent, or displays of gendered notions of trauma and vulnerability as markers of their authenticity,"47 are at a particular disadvantage. Thus, the male refugee claimants who cannot or will not conform to the expected notions of victimhood and the subsequent need for paternal protection may be excluded from refugee determination. Taking on this constructed subjectivity may be particularly difficult for male-identified claimants, since the dominant gendered expectations of appropriate masculinities often clash with the conceptualization of the traumatized and vulnerable victim. As Judge goes on to argue, those who cannot demonstrate the loss of agency necessary for these constructs risk being vilified and criminalized. ${ }^{48}$ Since the mid-199os, the Canadian government has actively instilled the metonymic association between the "bogus" refugee and the "foreign violent criminal." 49 The discourses propagating these associations are often extremely gendered and racialized, disproportionately affecting men of colour, who consequently need to be disciplined or excluded. Therefore, male-identified refugee claimants who are unable or unwilling to embody the appropriate victim narrative are constructed as fraudulent criminals who migrate to exploit social services or to commit violent acts against the state and its population. These perceived threats are then used to justify increased detention and ever-more-restrictive policies.

Pointing to another limitation, LaViolette analyzes the lack of consideration within the gender guidelines for all types of gender-based violence. Applying a socially constructed understanding of gender, she emphasizes that while women are the main victims of gender-based persecution, 
men and transgendered people can also experience persecution for challenging socially prescribed gender norms. She demonstrates how violence targeted towards people's sexual orientation could actually be more about their unwillingness to uphold social roles and norms than their sexual orientations..$^{\circ 0}$ She also points to specific cases in which transgendered individuals were not considered within gender-based analyses during their refugee claim, despite facing persecution precisely because of their gender identity. Finally, she examines two different situations where male refugee claimants could be considered within gender-based guidelines-compulsory military service and crimes of honour-and argues that men can be victims of many forms of gender and sexual violence in different contexts. Therefore, not only does gender need to be deconstructed to understand the social constructions and power relations involved, but the gender guidelines considered within a refugee determination hearing need to be understood as applicable in any case that involves gender-based persecution.

Another obstacle faced by refugee claimants in the recounting of their experiences of persecution are the preconceived ideas board members may have of the manner in which fear should be articulated. Though adjudicators profess to be neutral and objective, even these concepts are socially constructed and may be antithetical to cultural understanding of fear and vulnerability. ${ }^{51}$ Claimants must prove to IRB members that they are not only in danger, but also genuinely afraid. While the proof of danger may come in documented evidence, the subjective fear may be harder to identify. Evans Cameron suggests that board members have refused claims where the refugee claimant "acted in a manner inconsistent with a subjective fear of persecution." ${ }_{52}$ In these cases claimants may have stayed in their country longer than expected in the hope the threat would go away, travelled back to ease the pain of separation from loved ones, or delayed making a refugee claim after their arrival in Canada for whatever reason, yet board members may not accept these "naïve" explanations. 53

Moreover, as Rousseau et al. argue, the post-traumatic psychological effects that claimants may experience can also have significant impacts on the manner of recounting their narrative as well as on the content. 54 During the hearing, these effects may lead to avoidance, inconsistencies or mistakes, omissions, or late disclosures, which may be interpreted as a lack of credibility or genuine fear.55 Therefore, not only is the psychological ability of claimants overlooked in the demands of the hearing, but the limitations of claimants based on shame or humiliation experienced are ignored in the expectation that they will freely speak of their fear. Having reviewed Rousseau et al.'s findings, Steel, Frommer, and Silove also found that traumatized claimants often have great difficulty presenting a coherent account of the experience of traumatization with the expected affect, which may be interpreted by decision makers as not credible. ${ }^{6}$ While guidelines do exist for the identification and accommodation of vulnerable claimants, Cleveland argues that their application tends to be limited.57 Within these guidelines, vulnerable persons are defined as "individuals whose ability to present their case before the IRB is severely impaired," and adjudicators are advised to take specific considerations to ensure that these claimants are not disadvantaged. $5^{8}$ Cleveland goes on to explain that these vulnerabilities in refugee claimants are often a result of intersecting experiential factors and personal characteristics such as age, illness, or ability.59 While many claimants may have experiences and intersecting identities that make them vulnerable, only the most severe cases are identified within the guidelines for consideration. Cleveland points out that while many claimants are not designated as severe cases, and may be able to articulate their experiences, this is not without a significant personal cost. ${ }^{60}$ Therefore, ideas of ability/disability must also be deconstructed and considered more broadly in the determination of claims.

In addition, culturally based presentations of fear and understandings of how it should be managed may differ and thus be difficult to decipher by an IRB adjudicator. ${ }^{61}$ At the same time, claimants' articulations of their fear may not meet the gendered ways fear is expected to be experienced, managed, and performed. As a result, gender, race, and ability constructs play a role not only in what types of persecution can be experienced, but how those experiences of persecution are revealed to determining institutions. This process may, however, be subtle and even invisible in terms of the cultural clashes and misinterpretations, leaving both claimants and adjudicators unaware of the social constructs that delineated the hearing. ${ }^{62}$

The biases and preconceived ideas of adjudicators are particularly significant since the implementation of the Immigration and Refugee Protection Act in 2002, which reduced the number of board members determining each claim from two to one. With two adjudicators, so long as one believed the claim being made, the refugee claimant would generally be accepted. However, with only one person determining the credibility of a claimant's story, biases about how claimants should understand their situation, embody their identity, and represent their experiences can have significant impacts on their chances of regularizing their status.

According to Rehaag's preliminary research on the gender of the adjudicator and acceptance rates in Canada, male adjudicators had higher grant rates than females. These findings were even more pronounced when the 
principal claimants were women and the claims were based on gender-based persecution. While Rehaag's earlier research found that acceptance rates varied significantly between adjudicators, the initial incorporation of gender into the analysis adds a component for seeking patterns of correlations in outcomes. ${ }^{63}$ While Rehaag clearly outlines the limitations of the study and acknowledges the lack of intersectional analysis based on adjudicators' other identity constructs, his findings do leave interesting questions about the gender of applicants, board members, and corresponding acceptance rates.

\section{Protecting Canada's Immigration System Act}

The recent changes to the Canadian Refugee Determination System have significantly affected the processes navigated by refugee claimants. Timelines have been shortened dramatically, demanding that the refugee hearing take place between forty-five and sixty days from the time when the initial claim was made, as opposed to the previous one- to two-year wait. Specific determinations have also been made regarding Designated Countries of Origin (DCOs) or "safe countries," which are parliamentary democracies supposedly able to protect their populations, and Designated Foreign Nationals, whose travel to Canada is deemed inappropriate, including the use of smugglers and the crossing of borders in groups. These two designations restrict claimants in several ways, including additionally shortened timelines and lack of access to the newly instituted Refugee Appeal Division. Moreover, civil servants have replaced nominated board members. Refugee advocates, lawyers, and others have expressed their concern over these changes. The Canadian Council for Refugees outlined reservations about the changes, stating, "Consideration must be given to the need for claimants to properly understand and prepare for the process, to obtain necessary documents to support their claims, and to overcome fears they may have in regards to telling their stories of persecution to government authorities. Women, LGBTQ refugees, and others who have suffered torture and other forms of cruel and degrading treatment need time to properly prepare for the process." 64

The shortened timelines also make it more difficult to find and confirm experienced counsel, as lawyers are being asked to do more with less time and resources available; committed counsel can often identify the obstacles related to the identity constructs outlined and develop strategies to overcome them. Moreover, not only is it more difficult to obtain evidence of persecution from the country the claimant is fleeing in time for the hearing, but so too is the evidence necessary in Canada, including psychological or medical assessments, and documentary supports proving violence or persecution against specific individuals or groups. Finally, with less time to become aware of and prepare the "appropriate" performance of gender, race, sexuality, ability, and importantly, fear, based on specific Western constructs, this new adjudication could have significant implications for claimants seeking Canadian protection who cannot, will not, or do not know to conform. While few empirical studies have been published thus far on the impacts of the changes, I argue that many of the intersecting constructs outlined will continue to affect adjudication, with new identities potentially also having important implications. Further research is required to determine how these shifting intersectionalities will affect the process as well as the hearing itself.

\section{Conclusion}

As the related discourses continue to circulate, policies shift, and the immigration process becomes increasingly restrictive, it is important to understand the ways essentialized constructions of claimant subjectivities based on intersecting ideas of gender, race, ability, and sexuality limit people's possibilities for self-determination and increase the precariousness of their status. While the refugee hearing purportedly gives claimants the crucially important time and space to recount their narrative of persecution, the social constructs relied upon by adjudicators limit the experiences that are deemed acceptable and genuine. This article utilized an intra-categorical complexity approach to intersectionality to deconstruct the social constructs and power relations associated with different identity categories. While an attempt was made to challenge the "naturalness" of any particular identity category, the material implications of these categorizations were outlined to demonstrate their perceived importance within the refugee determination hearing. Broader understandings of identity are required in order to recognize the spectrum of claimants' experiences and avoid simplifying, de-politicizing, and criminalizing forced migration in all its contexts.

\section{Notes}

1 Cecile Rousseau, François Crépeau, Patricia Foxen, and France Houle, "The Complexity of Determining Refugeehood:AMultidisciplinaryAnalysisoftheDecisions-Making Process of the Canadian Immigration and Refugee Board," Journal of Refugee Studies 15, no. 1 (2002): 43-70.

2 Leslie McCall, "The Complexity of Intersectionality," Signs: Journal of Women in Culture and Society 30, no. 3 (2005): 1783 .

3 Marta Gimenez, "Marxism and Class, Gender and Race: Rethinking the Trilogy," Race, Gender \& Class 8, no. 2 (2001): 23-33; please also see Helma Lutz, Maria Teresa Herrera Vivar, and Linda Supik, eds., Framing 
Intersectionality: Debates on a Multi-Faceted Concept in Gender Studies (Farnham: Ashgate, 2011).

4 Marie Lacroix, "Canadian Refugee Policy and the Social Construction of the Refugee Claimant Subjectivity: Understanding Refugeeness," Journal of Refugee Studies 17, no. 2 (2004): 147-66.

5 Ruth Judge, "Refugee Advocacy and the Biopolitics of Asylum in Britain: The Precarious Position of Young Male Asylum Seekers and Refugees." RSC Working Paper Series no. 60 (2010), 20.

6 McCall, "Complexity of Intersectionality," 1771.

7 Rachel Silvey, "Power, Difference and Mobility: Feminist Advances in Migration Studies," Progress In Human Geography 28 , no. 4 (2004): 490-506.

8 Lutz, Herrera Vivar, and Supik, Framing Intersectionality, 4.

9 Katharine M. Donato, Donna Gabaccia, Jennifer Holdaway, Martin Manalansan IV, and Patricia R. Pessar, "A Glass Half Full? Gender in Migration Studies," International Migration Review 40, no. 1 (2006): 6.

10 Lutz, Herrera Vivar, and Supik, Framing Intersectionality.

11 Silvey, "Power, Difference and Mobility," 492.

12 McCall, "Complexity of Intersectionality," 1773.

13 Donato et al., "Glass Half Full?," 4.

14 Silvey, "Power, Difference and Mobility," 501.

15 Judge, "Refugee Advocacy," 11.

16 Nira Yuval-Davis, The Politics of Belonging: Intersectional Contestations (London: Sage Publications, 2011), 37.

17 Judge, "Refugee Advocacy," 11.

18 Citizenship and Immigration Canada, "CIC's Mandate, Mission and Vision," http://www.cic.gc.ca/english/department/mission.asp.

19 R. Bhuyan and T. Smith-Carrier, "Constructions of Migrant Rights in Canada: Subnational Citizenship Possible?" Citizenship Studies 16, no. 2 (2012): 203-21; please also see Canadian Council for Refugees, "Gender-Based Analysis of Settlement, Research Report" (2006), http:// www.ccrweb.ca/eng/issues/library.htm\#gender.

20 Anna Pratt and Mariana Valverde, "From Deserving Victims to 'Masters of Confusion': Redefining Refugees in the 1990s," Canadian Journal of Sociology 27, no. 2 (2002): 138.

21 Anthony H. Richmond, "Refugees and Racism in Canada," Refuge 19, no. 6 (2001): 12-20.

22 Gail Lewis, "Welcome to the Margins: Diversity, Tolerance, and Policies of Exclusion," Ethnic and Racial Studies 28, no. 3 (2005): 538.

23 Marie Lacroix, "Canadian Refugee Policy and the Social Construction of the Refugee Claimant Subjectivity: Understanding Refugeeness," Journal of Refugee Studies 17, no. 2 (2004): 149.

24 Rousseau et al., "Complexity of Determining Refugeehood," 43.

25 Canadian Council for Refugees, "The Experience of Refugee Claimants at Refugee Hearings at the Immigration and Refugee Board," Research Project (2012): 1-55.

26 Ibid., 66.
27 Ibid., 47.

28 Nicole LaViolette, "Independent Human Rights Documentation and Sexual Minorities: An Ongoing Challenge for the Canadian Refugee Determination Process," International Journal of Human Rights 13, nos. 2-3 (2010): 437-76.

29 Monica Boyd, "Gender Aspects of International Migration to Canada and the United States" (paper presented at the International Symposium on International Migration and Development, Population Division, Department of Economic and Social Affairs, Turin, Italy, 28-30 June 2006), 2.

30 Geraldine Sadoway, "The Gender Factor in Refugee Determination and the Effect of Gender Guidelines," in Not Born a Refugee Woman: Contesting Identities, Rethinking Practices, ed. Maroussia Hajdukowski-Ahmed, Nazilla Khanlou, and Helene Moussa (New York: Berghahan Books, 2008), 245.

31 Diana Mulinari, "Women Friendly? Understanding Gendered Racism in Sweden," in Gender Equality and Welfare Politics in Scandinavia: The Limits of Political Ambition?, ed. Kari Melby, Anna-Birte Ravn, and Christina Carlsson Wetterberg (Bristol: Policy, 2007), 169.

32 Susan Musarrat Akram, "Orientalism Revisited in Asylum and Refugee Claims," International Journal of Refugee Law 12, no. 1 (2000): 7-40.

33 Boyd, "Gender Aspects of International Migration," 23.

34 Carmela Murdocca, "Pursuing National Responsibility in a Post-9/11 World: Seeking Asylum in Canada from Gender Persecution," in Hajdukowski-Ahmed, Khanlou, and Moussa, Not Born a Refugee Woman, 258.

35 Jacqueline Bhabha, "Demography and Rights: Women, Children and Access to Asylum," International Journal of Refugee Law 16, no. 2 (2004): 227.

36 Judge, "Refugee Advocacy," 24.

37 Sadoway, "Gender Factor," 245; please also see Sean Rehaag, "Patrolling the Borders of Sexual Orientation: Bisexual Refugee Claims in Canada," McGill Law Journal 53 (2008): 59-102.

38 Rehaag, "Patrolling the Borders of Sexual Orientation."

39 David A. B. Murray, "Becoming Queer Here: Integration and Adaptation Experiences of Sexual Minority Refugees in Toronto," Refuge 28, no. 2 (2013): 130-2.

40 Sean Rehaag, "Patrolling the Borders of Sexual Orientation," 72.

41 Murray, "Becoming Queer Here," 129.

42 LaViolette, "Independent Human Rights Documentation," 451.

43 Ibid.

44 Murray, "Becoming Queer Here," 130.

45 Rehaag, "Patrolling the Borders of Sexual Orientation," 59.

46 Ibid.

47 Judge, "Refugee Advocacy," 8.

48 Ibid., 12. 
49 Pratt and Valverde, "From Deserving Victims to 'Masters of Confusion," 144.

50 Nicole Laviolette, "Gender-Related Refugee Claims: Expanding the Scope of the Canadian Guidelines," International Journal of Refugee Law 19, no. 2 (2007): 169- 214.

51 Rousseau et al., "Complexity of Determining Refugeehood," 50.

52 Hilary Evans Cameron, "Risk Theory and 'Subjective Fear': The Role of Risk Perception, Assessment, and Management in Refugee Status Determinations," International Journal of Refugee Law 20, no. 4 (2008): 567.

53 Ibid., 574 .

54 Rousseau et al., "Complexity of Determining Refugeehood," 48.

55 Janet Cleveland, "The Guideline on Procedures with Respect to Vulnerable Persons Appearing before the Immigration and Refugee Board of Canada: A Critical Overview," Refuge 25, no. 2 (2009): 119.

56 Zachary Steel, Naomi Frommer, and Derrick Silove, "Part I-The Mental Health Impacts of Migration: The Law and Its Effects. Failing to Understand: Refugee Determination and the Traumatized Applicant," International Journal of Law and Psychiatry 27 (2004): 517
57 Cleveland, "Guideline on Procedures."

58 Ibid., 120.

59 Ibid.

60 Ibid.

61 Evans Cameron, "Risk Theory," 584.

62 Rousseau et al., "Complexity of Determining Refugeehood," 51.

63 Sean Rehaag, "Do Women Judges Really Make a Difference?: An Empirical Analysis of Gender and Outcomes in Refugee Determinations," Canadian Journal of Women and the Law 23, no. 2 (2011): 628.

64 Canadian Council for Refugees, "Bill C31: Diminishing Refugee Protection," submission to Standing Committee on Citizenship and Immigration, Montreal, 2012): 9.

Tanya Aberman is a PhD candidate in Gender, Feminist, and Women's Studies at York University, Toronto. She is also an active volunteer at the FCJ Refugee Centre, supporting diverse newcomers in Toronto. She may be contacted at taberman@ yorku.ca.

(C) Tanya Aberman, 2014. This open-access work is licensed under a Creative Commons Attribution-NonCommercial 4.0 International License, which permits use, reproduction and distribution in any medium for non-commercial purposes, provided the original author(s) are credited and the original publication in Refuge: Canada's Journal on Refugees is cited. 